\title{
Study on Psychological Contract Based on
}

\section{Performance Communication}

\author{
Zhaojun Zhang \\ Wuhan University of Technology, Wuhan, 430070, China \\ Inner Mongolia University of Technology, Huhhot, 010051, China \\ E-mail: zzjnmgcn@sohu.com
}

Junling Zhang

Inner Mongolia University of Technology, Huhhot, 010051, China

The research is supported by Natural Science Foundation of Inner Mongolia (No. 200607010803). (Sponsoring information)

\begin{abstract}
Performance management is a durative intercommunication process, and psychological contract is unwritten concealed contract between organization and employee, which is a sort of subjective understanding and apperception. Through deep analysis of the effect of performance communication on performance management and psychological contract, this article puts forward the psychological contract violation communication model based on performance communication on the base of the psychological contract violation development model, and makes performance communication exert double functions that enhance the performance of organization and amend psychological contract among organizational members.
\end{abstract}

Keywords: Performance communication, Psychological contract, Violation communication model

Performance management is a durative communication process which is ensured to be completed by the agreement achieved between employees and their charge, and in the agreement, they will establish specific aim and understandings for the future work, and integrate possibly beneficial organizations, managers and employees into the performance system (Robert, 2002). The keys of performance include the durative communication process between manager (employees' direct senior) and employees, and the continuity and validity of performance communication.

Psychological contract will continually change with the change of the environment, and in the change process, to reduce the disagreement of understanding between two parties is very important, and full and effective communication will make the psychological contract between employees and organization achieve balance. Performance communication can offer the platform of communication for organization and employees, and through this sort of communication, the organization can find employees' potential abilities and further confirm the anticipation and demands between organization and employees. The confirmation of both demands can make for both parties to adjust themselves and finally achieve the coherence of psychological contract.

\section{Performance management is performance communication}

The work of performance management is completed by the superior and underlings together in the organization, and through both mutual cooperative means, i.e. communication, because this sort of performance management is beneficial for the developments of employees, manager and organization. The performance management is a sort of tool to improve bad performance and enhance performance together, and it means the superior should keep durative bidirectional communication with employees, and it is the process both learning and advancement together (Robert, 2002). For underlings, it is to enhance performance, and for superior, it is to enhance the ability of management. Therefore, one nuclear work of the whole performance assessment is the bidirectional communication, and the result of communication is to enhance the performance management level of the organization and increase mutual apperceptions.

\subsection{The meaning of performance communication for organization}

The performance management should serve for the perspective and strategy of the organization and promote that the organization realizes its task and objective, so every member in the organization should confirm what are the objective and task of the organization. When decomposing the objective, the communication becomes into one piece of important content for the organization, manager and employees. If the objectives of the organization and its 
interior underling departments are very clear and these objectives are associated with every employee's task, so the efficiency of the organization will be higher. When employees know the importance of their works for the success of the organization, their morale and productivities will be fully enhanced.

At the same time, when the organization decomposes the objective to concrete employees, every piece of objective should can be measured and assessed, and the organization, manager and employees should have same understanding to the object. The performance objective should be instituted by the line manager and underlings together, and completed through continual communications, and the human resource manager can not perform this work. Every department is a concrete performance management unit, and the line manager is the performance principal of this unit, and only the line manager has right to make objective known to lower levels and implement assessment.

\subsection{The meaning of performance communication for manager}

Some researches showed that many managers felt time was not enough, but why? When employees have no ideas about what they should do, how they should do and why they should do, it will certainly increase many works for the manager, because the problems that employees can decide are also sent to the desk of the manager. If employees have no enough understanding to their own works, they will hardly make good decisions, and even for very small problem, the manager have to make decision.

The performance communication is a sort of advance investment to make employees complete their works. Through performance communication, employees will know what the superior want them to do, what decisions they can make, how many degrees they can complete the work and when the superior must participate in. Only in this way, it is possible to allow manager to complete the work that only he can do, and accordingly the manager's time is saved. Through communication, the manger can help underlings to enhance their abilities, comprehensively know employees work situations, grasp the information of work headway, offer corresponding special assistance and resource, effectively grasp the proofs of the assessment and objectively and justly assess underlings' work performances, enhance the manger's validity of the work, and enhance employees' satisfactory degrees to the performance assessment and the encouragement mechanism closely correlative to the performance assessment.

\subsection{The meaning of performance communication for employee}

Because the performance management is a process to complete the work with employees together, so the manager has to make employees know the benefits for them and ask employees how to do the work better. Usually the performance managements of some enterprises have not achieved the anticipated effects, and one reason is that managers have not realized the importance of performance communication. The performance management requires periodic and aperiodic communications between managers and employees, and which can make employees obtain the feedbacks about their work performances and work actualities. The performance management can help employees clarify what they should do and why they do this, and make employees continually amend their bad aspects in their performances in the process. So the performance communication offers possible opportunity to help employees to enhance their skills and find reasons why the performance is baffled, for example, the raw material is unfitted.

The communication can help employees continually obtain the feedback information about their work performances such as customers' grumbles, the shortage of the work, the deficiency of product quality and other information, in order to continually amend their warps and enhance their skills, and can help employees timely know the objective adjustment of the organization and the change of work importance in order to properly alter their individual objective and work task, and can help employees timely obtain assistants from the superior and achieve the objective better.

\section{Effects of performance communication on psychological contract}

Robinson further defined the psychological contract, and he pointed out that the psychological contract was a series of faith of mutual obligation between one employee with his obligation, and these faiths were based on the subjective understanding to the promise (Morrison E W \& Robinson S L, 1997, p.226-256). That is to say, the psychological contract is a sort of subjective feeling which has the character of subjectivity, and this sort of subjectivity decides the specific cognitions what and how much every employee should contribute for the organization and what and how much the organization should return to him. These contents influence employees' work attitudes and behaviors simultaneously.

One distinct character of the psychological contract is the dynamic character, and the psychological contract will change with continual changes of time and environment. Meuse, Bergmann and Lester (2001) pointed out that the psychological contract will change with the process of time, especially in a long-term. Their researches found that in 
different ages, employees' psychological contract level (actually it means the satisfactory level of psychological contract) had different obvious representations, i.e. with the development of age, the psychological contract basically presented downtrend (Rousseau D M, 1982, p.121-139).

\subsection{Durative performance communication can help organization and employee to share information together}

Robert Bacal had pointed out that the performance management cycle begun form the plan, and ended by review or evaluation, but the most effective stage that made the method of performance management exerted functions was the durative communication in the middle of plan and evaluation (Robert, 2002). One intention of durative performance communication is to keep the work process is dynamic, soft and sensitive. The communication can timely modify objective and work task, and can eliminate the disagreement of understanding to the psychological contract between organization and employees.

Some researches showed that the more information both employees and organization know each other, the more coherence both understanding will achieve. Through making the performance management turn into a sustainable process of information communication and feeling communication, the organization can exert the function of performance management, influence manager and employees' subjective understandings, which doubtlessly accords with the subjectivity and dynamic character of the management of psychological contract, and durative communication will make the difference between psychological contract and anticipation and organizational promise reduced, and make both anticipations and demands known more profoundly and comprehensively, and keep the dynamic coherence of psychological contract.

2.2 The performance feedback process can promote communication and influence the psychological contract between organization and employee

Through performance management, the organization can assess employees' competence degree to the work, measure their work developmental potentials, find employees advantages and shortages, institute relative training projects and make training measures and plans implement favorably, improve the communication between superior and junior and make both know their anticipations each other, and more understandings can reduce more subjectivities of the understanding. If the intention of the performance management wants to be realized, it should implement effective and durative communication, timely feed back information obtained through assessment and employee's behaviors.

The performance feedback is one piece of important content of performance management. The basic meaning of feedback is the information about individual past behaviors. The feedback can offer employees' information about their past behaviors, and the information about their abilities, individual controls and exterior encouragements. Some researches found that the performance feedback can not only help individuals adjust their self-perceptions, self-assessments and behaviors, but can enhance their self-managements (Robert, 2002). At the same time, the information fed back to employees can make employees timely know the demands of enterprise, and exactly understand the attitude of the enterprise to enterprises. Both combinations can make employees go to the scheduled individual and organizational objectives, which can not only make for performance improvement, but promote employees and organizations to realize their own anticipations and demands, and achieve the coherence of both psychological contract.

\section{The amending function of performance communication to psychological contract}

The performance communication not only is the powerful tool that organization continually enhances the performance, but makes for knowing anticipations and increasing mutual perceptions, and exerts the function of modification and adjustment for the psychological contract.

\subsection{Durative communication will clarify psychological contract}

The communication process model constructed by the famous scholar Stephen P. Robbins (1997) possessed representative character, and this model included 7 parts including communication information resource, coding, information, channels, decoding, receiver and feedback. The model is seen in Figure 1.

Rousseau thought that the psychological contract was mainly based on employees' individual perception to the organization, and the theoretical model put forward by her took the individual psychological process to the environment and the society (Rousseau, 1982, p.121-139). The construction model of psychological contract is seen in Figure 2.

As viewed from the communication model, the communication is the process continually implementing coding, decoding and feedback to information. And as viewed from the construction model of psychological contract, the psychological contract is the process implementing coding, decoding and considering organizational factors to various filtrated information. The psychological contract possesses the characters of subjectivity and dynamic 
character, and the content of psychological contract is a sort of individual subjective feeling, special experiences and opinions to mutual responsibilities. In this way, individual psychological anticipation may differ from the anticipated content of enterprise, and may differ from others' understandings. Through the comparison of two models, the communication has natural association with psychological contract, but in the process of the formation of psychological contract or coding and decoding, durative communication can achieve the coherence of psychology contract between individual and organization.

At the same time, the psychological contract has dynamic character. The formal employment contract is generally stable, but the psychological contract is in a sort of state which is continually altered and modified. Any changes about relative work forms of organization, such as the alteration of leader, the change of communication form and the change of organizational culture will influence the psychological contract. The longer time that individual works in the organization, the more extensive range that the psychological contains and it is more easily influenced by various factors (Perter, 2000). Therefore, when some factors in the organization change, the organization should reveal enough information to individuals in order to adjust the content of psychological contract, which all need durative performance communication.

\subsection{Durative communication will amend psychological contract violation}

With the fury competition, the continually mutative exterior environment and the continual increase of possibility that the employee psychological contract is violated, this problem has become into the hotspot in this domain. Morrison and Robinson summarized the researches of the concept of psychological contract violation, and they thought unimplemented psychological contract would produce corresponding perception assessment and feeling reaction, and a complex explanation process existed between them, and the separation between the perceptions of unimplemented promise with the violation reaction produced by this should be emphasized (Morrison E W \& Robinson S L, 1997, p.226-256). They thought the former meant individual's perception assessment of responsibility assumed by the organization which can not complete the responsibility in the psychological contract, which was called the un-implementation of psychological contract. The later meant one sort of emotional experience produced by the individual when the organization can not completely perform the psychological contract, which core was indignation and disappointment and came from that the organization was perfidious or the individual suffered unfair treatment, which was called the violation of psychological contract.

Some researches showed that the un-implementation of psychological contract would not induce negative reaction, but violation would induce negative influence to employees' attitudes and behaviors. For example, in one lengthways research, Robinson, Kraatz and Rousseau found that the violation of psychological contract negatively influenced employees' perceptions to the obligation of the organization (Robinson, 1994, p.137-152). Robinson and her colleagues' same investigation result showed that employee's perception to contract violation was associated with some unfavorable behaviors such as the increase of demission rate and the decrease of work performance. Therefore, the un-implementation of psychological contract differs with the violation of psychological contract, and there is a complex explanation process in this term. The reaction of employee contract violation is very adverse to the organization, and if one adjustable factor would prevent that the un-implementation of psychological contract changes to the violation and even the occurrence of un-implementation, which has important meanings to both organization and employees. This article put forward the psychological contract violation communication model based on Morrison and Robinson's psychological contract violation development model, which is seen in Figure 3.

The violation communication model opens out that before the psychological contract is performed, durative communication can reduce and eliminate the incoherence of indisposition, uncertainty, illegibility and understanding, and there is a comparative process perceived from the un-implementation of contract to the violation of contract and the communication will increase the relativity and make the comparative information more specific, and there is a explanation process perceived from the un-implementation of contract to the violation of contract and employees will find the reason and justice of violation, and if the communication is adjusted timely, employees' evaluation will develop to the active aspect, and before the employee makes the reaction of violation, the factor of communication can reduce the employees' reactions of violation.

\section{Conclusions}

To sum up, the performance communication goes through the process of performance management, the whole operation process of enterprise, and the formation and development process of psychological contract. Through the mutual endeavors of manager and employees in performance communication, the organization can timely deal with arisen problems, the superior and junior can obtain information each other in the equal intercourse, increase understandings and feelings, and ensure that the work process is dynamic, soft and sensitive, and enhance the performances of organization and employees. In the psychological contract management, the organization should 
pay attention to exert durative performance communication, ensure the continuity and validity of performance communication, and accordingly increase both perception, and exert the function to amend the un-implementation and violation of psychological contract.

\section{References}

Chen, Jiazhou, Ling, Wenquan \& Fang, Liluo. (2003). Content, Dimension and Type of Psychological Contract. Advances in Psychological Science. No.4.

Morrison E W \& Robinson S L. (1997). When Employees Feel Betrayed: A Model of How Psychological Contract Violation Develops. Academy of Management Review. No.22(1). p.226-256.

Perter Markin (Britain). (2000). Organization and Psychological Contract. Beijing: Peking University Press.

Robert Bacal (US), interpreted by Chen, Zhouping. (2002). Performance Management. Beijing: Chinese Standard Press.

Robinson S L, Kraatz M S \& Rousseau D M. (1994). Changing Obligations and the Psychological Contract: A Longitudinal Study. Academy of Management Journal. No.37. p.137-152.

Rousseau D M. (1982). Psychological and Implied Contracts in Organizations. Employee Responsibilities and Rights Journal. No.2(2). p.121-139.

Shen, Xuewu. (2005). Study on Psychological Contract Violation and Interference. Wuhan: Doctor Dissertations of Wuhan University. May, 2005.

Sun, Jianmin \& Xu, Shiyong. (2006). Management Communication. Beijing: Tsinghua University Press.

Turnley W H \& Feldman D C. (1999). Psychological Contract Violations during Organizational Restructuring. Human Resource Management. No.37. p.71-83.

Weifeng \& Zhang, Wenxian. (2005). New Development of Psychological Contract Research. Journal of Management Sciences in China. No.5.

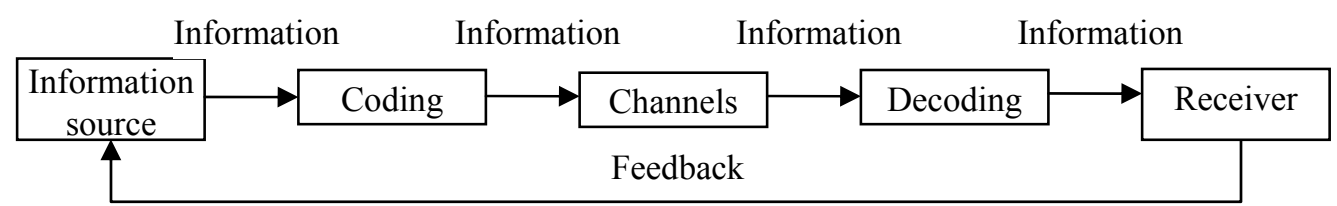

Figure 1. Communication Process Model

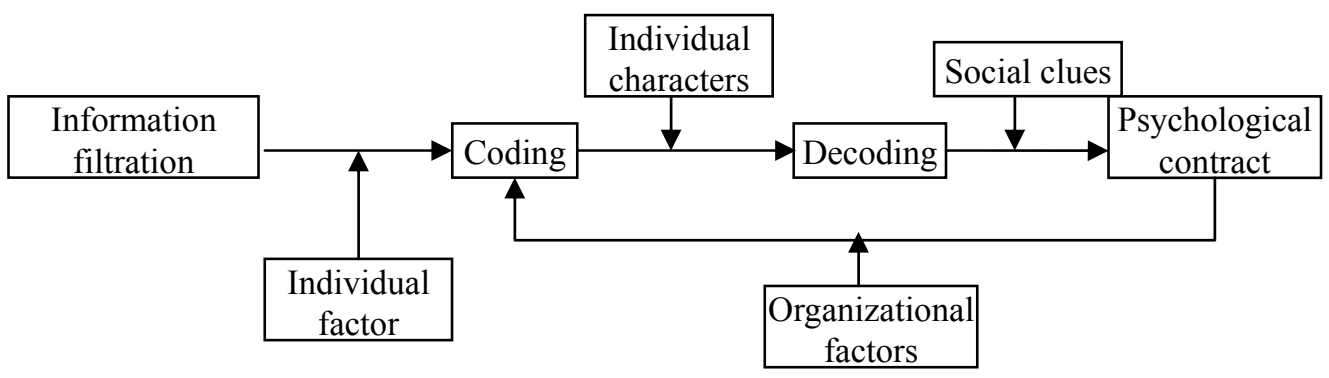

Figure 2. Construction Model of Psychological Contract 


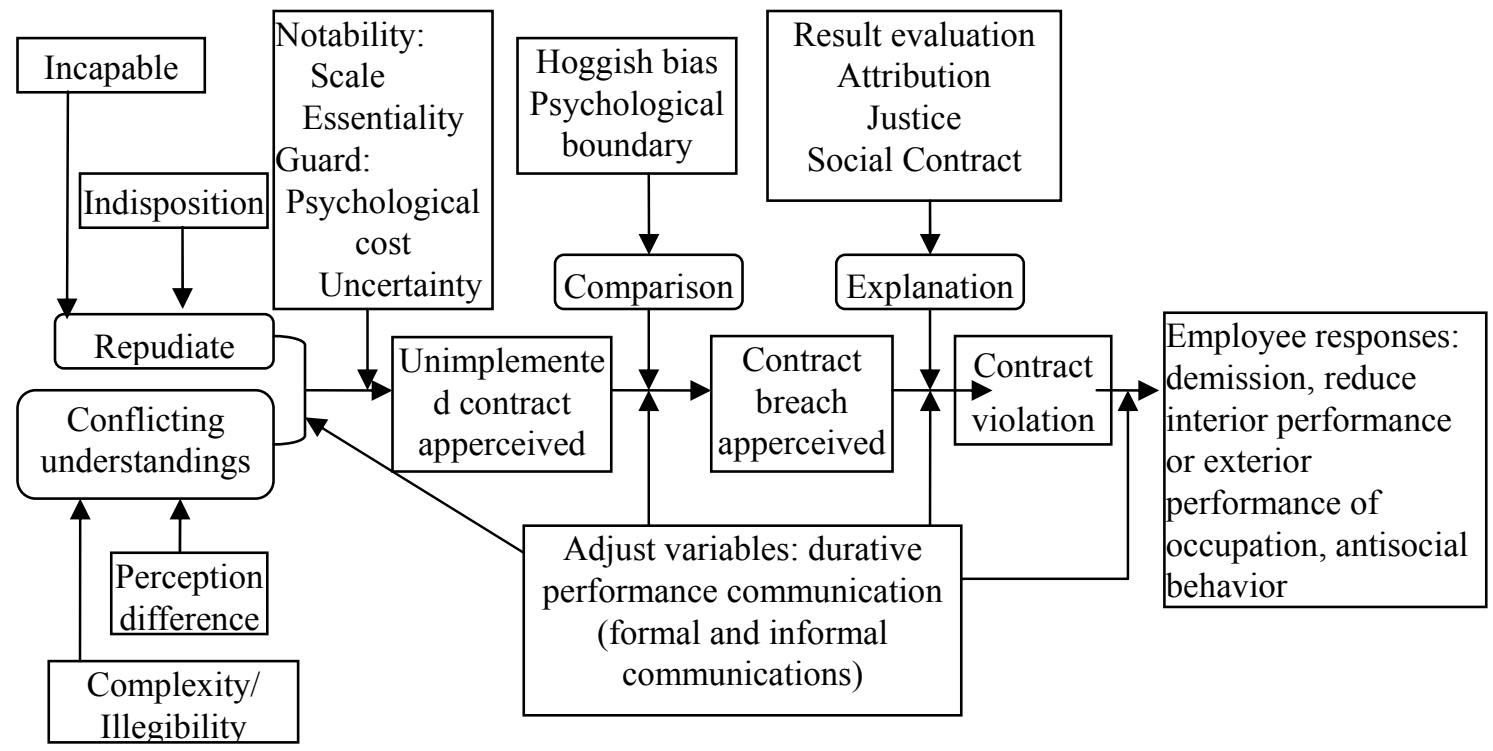

Figure 3. Violation Communication Model 


\title{
Enterprise Risk Management Implementation
}

\section{Model for Airport Operators in Turkey}

\author{
Ayse KUCUK YILMAZ \\ Anadolu University. 2 Eylul Campus. School of Civil Aviation. 26470 Eskisehir, Turkey \\ GSM: +905354625590Ｅ-mail: akucukyilmaz@gmail.com
}

\begin{abstract}
This paper aimed to developing of new ERM framework model for airport operators in the Turkey. The model is developed by collaborative study with DHMI (Turkey Governmental Authority to airport), TAV Airport Holding Co. and Celebi Holding., which they are leadership in the airport operators in the Turkey. The verbal model is used in the developing of the ERM model. Current ERM models are re-interpreted and shaped according to the Turkish airport operators. In the study, Questionnaire is applied and face-to-face interviews are made with airport managers to developing of the effective and applicable ERM model to airport business. The Istanbul-Atatürk International Airport in Turkey is selected a sample to ERM model as real world situation that there is prior international airport in the Turkey.
\end{abstract}

Keywords: Airport operator, Enterprise risk management implementation model

\section{Introduction}

Airports cannot be seen as just another industry. However, due to fundamental changes in the market and competitive landscape, pressure and risks on airports will increase significantly. Airports have to move towards transparent management structures with an explicit focus on the core business and clear accountability. They are present of importance and necessity of ERM implementation at airport.

The objective of this study is developing of ERM Model for the Istanbul-Atatürk International Airport in Turkey. Collaborative study is carried out with airport's executives during the application of ERM model. The model emphasizes that ERM is an integral part of the management process. Allocation and use of limited resources through an effective and systematic ERM implementation effort are critical in Turkey as well as other developing countries. Implementation of ERM model can able to provide reasonable assurance to managing risks of airport business.

The paper organized into 4 sections and begins with the ERM and related researches. Problem and Proposed ERM Model are presents in Section 3. Results are explained in Section 4 and concluding remarks is given this last section.

\section{The Enterprise Risk Management and related researches}

ERM literature is vast context. Many organizations is publishes various studies about ERM. In this study, source samples about ERM given as following;

(1) COSO Enterprise Risk Management-Integrated Framework: The framework defines essential ERM components, discusses key ERM principles and concepts, suggests a common ERM language, and provides clear direction and guidance for ERM. Engaged by COSO to lead the study, PricewaterhouseCoopers was assisted by an advisory council composed of representatives from the five COSO organizations (COSO, 2004).

(2) Enterprise Risk Management: Frameworks, Elements, and Integration (2006): Statements on Management Accounting (SMAs) present the views of IMA regarding management accounting and financial management issues. In their development, the Statements are subjected to a rigorous exposure process. The 2006 SMA on Enterprise Risk Management: Frameworks, Elements, and Integration provide an overview of the ERM process and frameworks and will help management accountants understand their roles and responsibilities in ERM projects (IMA, 2007).

(3) Enterprise Risk Management: It's Implications, Benefits and Process (2006) publishes by General Re. According to the resource, ERM has come out from behind the curtain. All insurers, to some degree, will have to begin assessing their risk management capabilities and processes. ERM is a good business practice and companies can turn the new ERM standards set by rating agencies into a competitive advantage. If companies look beyond "Checking the box" for meeting rating agency criteria, the real value of ERM can be realized and result in more profitable business practices down the road. This paper describes the ERM process, its benefits and implication. We will then examine how the rating agencies have taken up ERM as an important aspect of the rating process. 
(4) The Principles of Enterprise Risk Management is publishes by Virchow, Krause \& Company. According to the study "ERM can be tailored to any utility's operations. In today's utility environment operating without ERM principles in place is taking a gamble that nothing will go wrong, or that you will be successfully reactive to factors impacting your business. You wouldn't run your personal household that way, would you? This paper explains the journey into the intricacies of understanding and implementing an ERM program at your utility or organization. To fully understand the mindset and process behind ERM, we must first discuss the founding principles of ERM and its application in various industries" (Virchow, Krause \& Company, 2006)

(5) Enterprise Risk Management: Theory And Practice (2006) is published by Ohio University. In this paper, they explain how ERM creates value for shareholders. In contrast to the existing finance literature, we emphasize the organizational benefits of risk management. They show how a firm should choose its risk appetite and measure risk when implementing enterprise risk management. They also provide an extensive guide to the implementation issues faced by firms that implement ERM (Stulz \& Nocco, 2006).

(6) Enterprise Risk Management: Specialty Guide (2006) is publishes by Society of Actuaries. The Society of Actuaries has undertaken an initiative to educate the public, and especially industry leaders who are in need of guidance in matters involving risk assessment and control, about actuaries' unique set of skills that are particularly relevant in today's climate of risk quantification, classification and mitigation. This Specialty Guide on ERM is a work in progress, begun in the spring of 2004 by members of the ERM Working Group of the Society of Actuaries Risk Management Section to serve as a fundamental resource for a basic understanding of ERM, as well as a guide to further study of the subject (Society of Actuaries, 2006).

Many resources, guidelines and surveys are publishes in ERM literature. But any research or guide doesn't exist about airport ERM. Therefore, the study is aimed to contribute for this field.

\section{Problem and Proposed ERM Model}

The study is dealing solving with "What kind of ERM model should develop to airports in Turkey" main problem. ERM implementation is not "one-size-fits-all" kind approach to any organizations. So, every organization should develop their ERM implementation model and its process. This paper aimed to developing an ERM framework model for airports in Turkey. The model is developed by collaborative study with DHMI (Turkey Governmental Authority to airport), TAV Airport Holding Co., and Celebi Holding, which they are leadership as the airport operators in the Turkey. The verbal model is used in the developing of the ERM model. For this aim, Current ERM applications are analyzed and ERM guidelines/frameworks are reviewed. Current ERM models are re-interpreted and shaping for airports. Also this new model is clings to current ERM framework by publishes COSO.

In the study, Questionnaire is applied and face-to-face interviews are made with airport managers to developing the effective and applicable ERM model to airport business. The Istanbul-Atatürk International Airport in Turkey is selected a sample to new ERM model as real world situation that it is prior international airport in the Turkey (Kucuk Yilmaz, 2007).

As illustrated in figure-1., new ERM model is consist to 32 steps: 6 main steps and its sub-step. They are listed following (Kucuk Yilmaz, 2008);

(1) Analysis of internal environment and determination of requirements of ERM

a. Declaration of organizational objectives and aims

b. Determination of external and internal pressures (with their risks)

c. Analysis of internal audit structure

d. Analysis of information systems

f. Determination of organizational resource and their allocation

g. Determination of organizational strategy and its relationship with ERM

h. Supporting of ERM by the current managerial approaches, applications and functions: strategic management and planning, corporate governance, line management, portfolio management, value management, etc.

(2) Establish of ERM strategy; Establish of substructure requirements about ERM

a. Definition of organizational ERM vision, mission and strategy that they are guide and shaped to ERM model

b. Determination of current ERM and risk perceptions, ERM and risk culture by using of the different analysis techniques

c. Determination of useful ERM guidelines and reports, best practices; Decision making of which guides are using to developing ERM model 
d. Develop a common risk language and ERM terminology

e. Analysis of organizational capabilities, abilities according to the desired ERM model and its implementation efforts.

f. Training and education about fundamental ERM concepts, conceptual framework, process and practice steps for managers and related other staff in airports.

g. Building of organizational risk profile and determination of risk tolerance line.

(3) Establish of ERM function and committee

a. establish a suitable ERM function

b. Place of the ERM Committee (CEO, CRO, CFO, CIO, etc.) in organization chart.

(4) Establish of ERM information system and determination of ERM framework

a. Establish suitable ERMIS (Enterprise Risk Management Information System)

b. Establish Documentation procedures and format

c. Establish reporting format and line (top-down, across, down to top, external and internal parties)

d. Benchmarking of the best ERM framework to airport by analysis other ERM models in the guidelines and reports

e. Decision making and establish of the suitable ERM framework

f. Determination of the risk identification tools, methods and models ; Definition of current and possible risks to airport

g. Determination of the risk assessment tools, methods and models

h. Assessment of the risk analysis result as their impact and severity

i. Classification of risks in the four main categories: strategic, financial, operational and threat risks,

j. Risk mapping and Risk prioritization

$\mathrm{k}$. Selection and application of agreeable risk responses

1. Establish continuously monitoring and review function

(5) Data flow and feedback; Analysis of ERM implementation performance

a. Update and improving of the ERM system

b. Provide effective and well-timed data flow and feedback line and the determination of their context

c. Assessment of the organizational ERM application performance in respect of the both system and the related managers \& staff

(6) Provide continuous improvement \& development about ERM Process

Provide continuity both ERM system and its improving; Restart to ERM process over loop to new and developing risk and environment

This model is ERM framework to implementation in the airport. It has serial steps. Every sub-step is sufficiently explaine to "what should do related main steps".

Main research problem is developing of best and suitable ERM framework model and its appropriate adaptation for airports. This study is focus on this problem and its solution.

Verbal model is used to developing of new ERM model. As a known, verbal models tell the real system or process with words. In these kinds of the models components and relationships are define with words. In this study, main and detailed steps are developed as arranged in order. Verbal models use words to represent some object or situation that exists, or could exist, in reality. Verbal models may range from a simple word presentation of scenery described in a book to a complex business decision problem (described in words and numbers). A firm's mission statement is a model of its beliefs about what business it is in and sets the stage for the firm's determination of goals and objectives (Encyclopedia of Management, 2006).

The study is prepared according to the Istanbul-Atatürk International Airport in Turkey. The implementation of the ERM model is not a "one-size-fits-all" analysis. So, the model is tailored according to the qualifications and various parameters of the Turkey Airports and especially to the Istanbul-Atatürk International Airport. All efforts achieved with coordinated studies with airport managers in the Turkey as following steps:

a. Turkey airports are analyzed about ERM infrastructure and capabilities, objectives and wants related ERM. 
b. The model tailored according to the determinations.

c. Basic ERM framework and process is prepared according to the general ERM context.

d. ERM model integrated with organizational ERM process.

e. ERM Information Management System (ERM-IMS) developed as shown figure 2.

ERM information management systems are designed to overcome the problem of aggregating data across the organization. The design of an information system depends on the risk measurement methodology that a firm chooses. The current and likely future improvements in risk management information systems make feasible new ways of collecting aggregate data on firms' risk-taking activities. The problem of designing an information system for risk management is a problem of aggregation (Gibson, 1997).

\section{Results}

Developed ERM model is generally implemented in International Istanbul Airport because of the scope of this study, characteristics of the subject and time for giving results. The model implementation executed with high level airport managers as coordinated studies. The model and implementation results are presented to these managers. They are started efforts related in establish ERM framework in their airports since 2006. This can be considered as study's contribution to airport sectors.

Any framework model not exists in the world and Turkey according to the airport ERM implementation. Also, the any conceptual and theoretical study doesn't exist in Turkey about ERM. In this concept, suggested model is prepared as to answer these deficiencies. However Fraport A.G. has successful ERM system. Their system is analyzed during the study preparation process. Sydney airport has integrated risk management system. Finally, an ERM practice has very narrow airport business samples across the world.

The Istanbul-Atatürk International Airport is selected as research sampling in this study which there is biggest and prior airport in the Turkey. The study is separate and superior from other frameworks in the ERM guides and reports since the study focused critical elements for the airports. They are;

a. External and internal pressures to the airport management

b. Airport risks as enterprise wide: strategic, financial, operational and threats risk categories

c. ERM committee structure

d. ERM implementation process and their steps

e. Critical success factors

f. Integration of ERM to organizational structure

Completed and achieved studies within this research period are given following order:

a. A questionnaire as a qualitative research technique is prepared to investigate perception and approach of ERM across organization and their personnel. This questionnaire, including structured and unstructured question sets, is applied to major airports. Questions of questionnaire are prepared to demonstrate risk and ERM perceptions with other substructure elements of effective ERM. Also, the questionnaire is prepared to determine the situation and dimensions of governance since ERM interrelated with corporate governance, strategic management, strategic planning, organizational objectives and mission of enterprise.

b. Applicability analysis of ERM is achieved for all airports in Turkey. Results of this analysis used to determination of current situation of ERM substructure. Also, main requirement and deficiencies are determinates with this study.

c. New ERM framework model is created for airports and integrated general ERM process. The model offered to airport managers to establish their system.

d. ERM age started in the Turkey's air transportation sector: airports and airlines. This is an important development for Turkey civil aviation sector.

The fact that the nature and importance of air transport is changing has long been recognized.

In Turkey, ERM implementation is apply by TAV Airport Holding Co. since 2006 as full ERM concept. TAV is unique sample related to ERM in the Turkey. However, other airport managers are willing to increase the awareness for ERM at level of corporate. Their efforts are improving across their organizations in this field. Turkey's air transportation sector and airports do pay attention to the ERM implementation with start of the study. Having in mind the compliance efforts to entrance to the European Union, airport managers have to start their practice towards the establish and implement of ERM and it will require strong effort inevitable for gaining new knowledge and experience in application of the active principles of ERM. ERM simply enables management to operate more 
effectively in environments filled with risks, and in volatile markets such as Turkey (Kucuk Yilmaz, 2006).

\section{Acknowledgements}

The study is based on: Ayse Kucuk Yilmaz, Enterprise Risk Management Implementations and the Model Suggestion to the Airports in the Turkey, Doctoral Dissertation, Anadolu University, Eskisehir, Turkey, 2007"). The Author would like to thank the managers who assisted with this research: TAV CEO M. Sani SENER and other TAV managers; Ferda YAKAR and Musa GUNGOREN are high level managers of the Celebi-Ic Holding, at Turkey.

\section{References}

Casualty Actuarial Society Enterprise Risk Management Committee, (2003). Overview of enterprise risk management. [Online] Available: www.casact.org/research/erm/overview.pdf (January 07, 2008)

Coleman, G., \& Boothroyd, K., (2007). ERM within AMEC: process, practice and lessons learned, [Online] Available: http://www.theirm.org/events/documents/AMECpresentation.pdf (February 25, 2008)

Encyclopedia of Management, (2006). Models and Modeling. [Online] Available:

http://www.referenceforbusiness.com/management/Mar-No/Models-and-Modeling.html, (December 12, 2007)

Gibson, Michael S., (1997). "Information Systems for Risk Management," in Bank for International Settlements, The Measurement of Aggregate Market Risk, 115-132

Institue of Management Accountants (2007), Enterprise risk management: tools and techniques for effective implementation. [Online] Avaliable: www.mgt.ncsu.edu/erm/documents/IMAToolsTechniquesMay07.pdf

The Committee of Sponsoring Organizations of the Treadway Commission (COSO), (2004), Enterprise risk management. [Online] Available: www.erm.coso.org. (October 19, 2007)

Kucuk Yilmaz, A. (2008), Airport Enterprise Risk Management Model: A Study on Business Management and Airline Management. Chapter V. VDM Verlag Dr. Müler, Germany

Kucuk Yilmaz, Ayse (2007). Enterprise risk management implementations and the model suggestion for the airport business in the Turkey. Unpublished doctoral dissertation, Anadolu University, Eskisehir, Turkey, 2007.

Nocco, B. W., \& René M. Stulz, (2006). Enterprise risk management: theory and practice, [Online] Available: www.cob.ohio-state.edu/fin/faculty/stulz/publishedpapers/184_nocco.pdf (December 18, 2007)

PricewaterhouseCoopers, (2006), Enterprise risk management benchmarking survey 2006, [Online] Available: www.pwc.com/fi/fin/about/svcs/neuvonta/erm_study_2006.pdf(December 06, 2007)

Society of Actuaries, (2006). Enterprise risk management specialty guide. [Online] Available: www.soa.org/.../enterprise-risk-management/2005/august/spg0605erm.pdf (February 25, 2008)

Virchow, Krause \& Company, (2006). The principles of enterprise risk management, [Online] Available: http://jobfunctions.bnet.com/Operations/Business+Security/Enterprise+Risk+Management/ (February 25, 2008). 
ERM Inqlementation Model to Airports

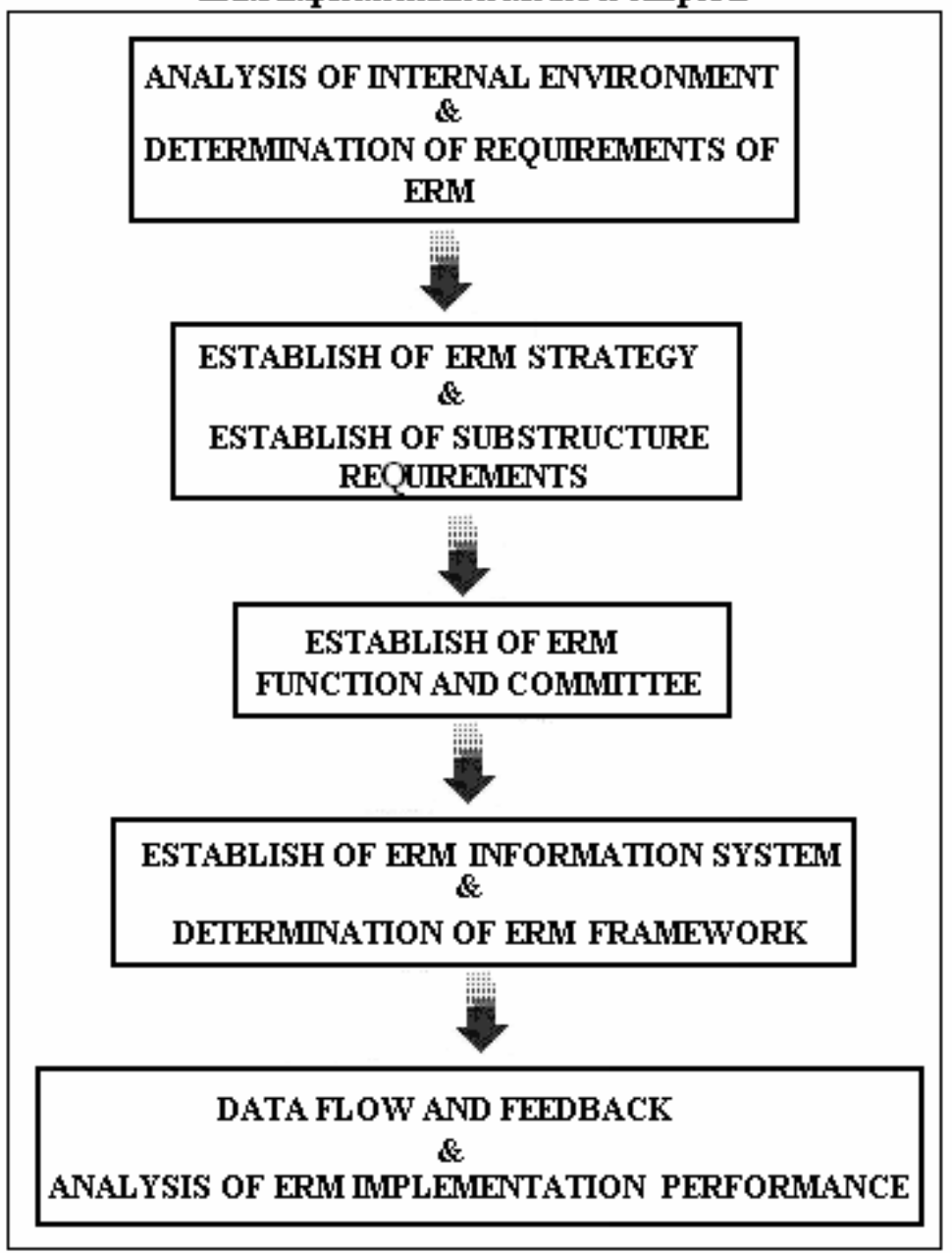

Figure 1. The new ERM implementation model (Kucuk Yilmaz, 2007). 


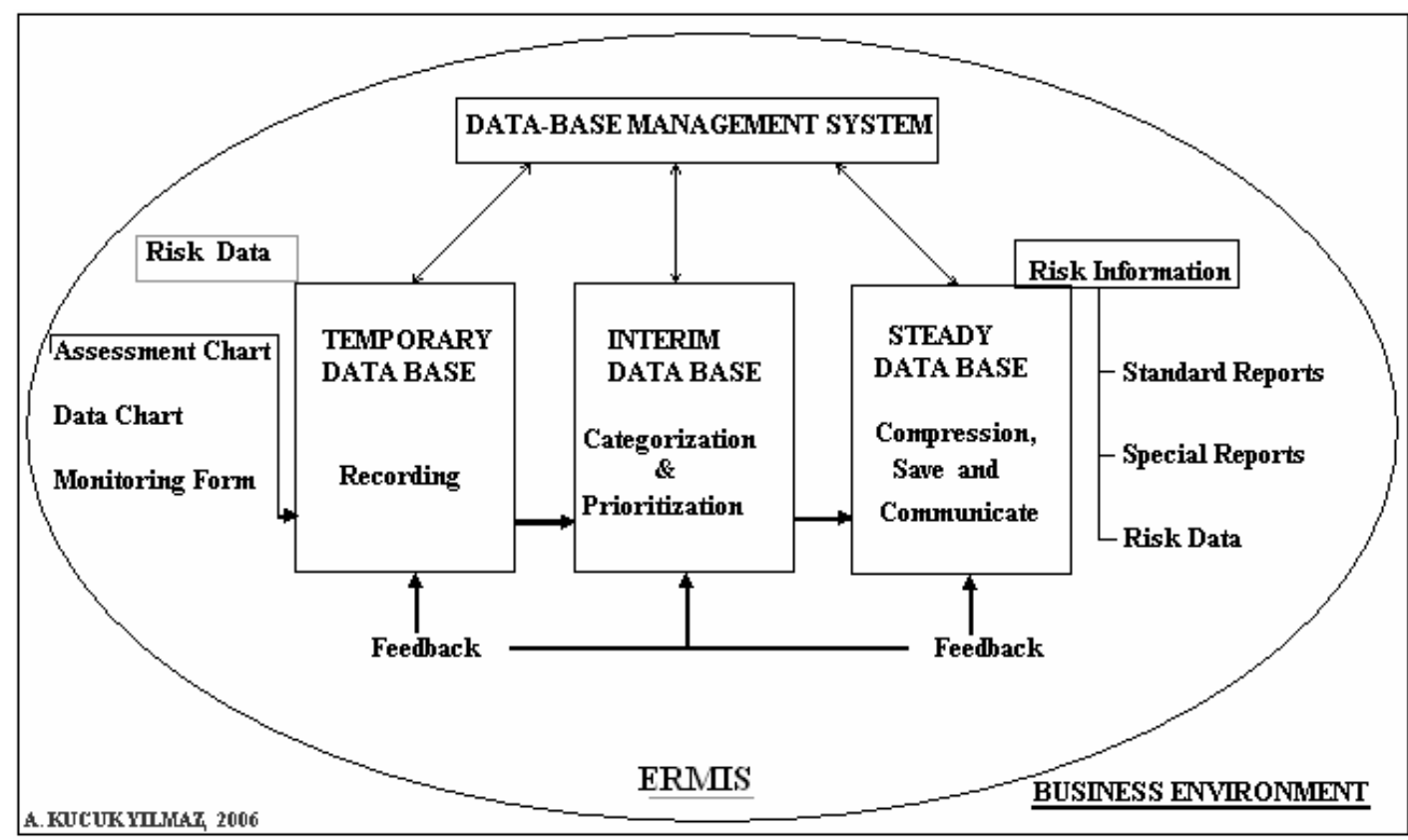

Figure 2. The ERM information system, (Kucuk Yilmaz, A. 2007). 